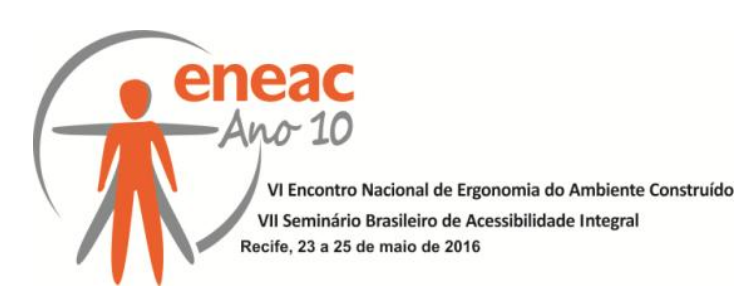

\title{
POR UMA INTERSEÇÃO ENTRE A ERGONOMIA E O PROJETO DE AMBIENTES CONSTRUÍDOS
}

\author{
COSTA, Ana Paula Lima \\ UFPE, Mestre em Design \\ e-mail:aplimacosta@gmail.com
}

\begin{abstract}
RESUMO
Este artigo buscar discutir o processo de projetação dos ambientes construídos, considerando o objetivo de responder às necessidades dos usuários, versando-se sobre a utilização de uma abordagem ergonômica para focar as interações entre o ambiente e o usuário. Para tanto, deve-se examinar os efeitos do ambiente sobre a pessoa, passando a variabilidade humana a ser um parâmetro de projeto no qual se considera as capacidades e limitações dos indivíduos.
\end{abstract}

Palavras chave: metodologia de projeto, arquitetura, ergonomia do ambiente construído

\begin{abstract}
This article discusses the design process of the built environment, considering the purpose of meeting the needs of users, whether dealing on the use of an ergonomic approach to focus on the interactions between the environment and the user. To do so, one must examine the effects of environment on the person undergoing human variability is a design parameter which is considered in the capabilities and limitations of individuals.
\end{abstract}

Keywords: design methodology, architecture, environmental ergonomic built

\section{INTRODUÇÃO}

O projeto de uma edificação é um processo compositivo que tem como objetivo a materialização de um desejo, englobando o entendimento das circunstâncias e das possibilidades em que esse desejo se explicita (IAB, 2013). Considerando que o projeto deve atender a requisitos a serem atendidos pela edificação, o ambiente construído deve apresentar características físicas de caráter prático-utilitário, tais como: dimensionamento, sistema de circulação e condições acústicas, que correspondem aos aspectos mecânicos da função e da atividade desenvolvida no ambiente, incluindo as atividades biológicas do organismo (GRAEFF, 1986).

O conjunto de fatores humanos a serem atendidos no processo de concepção exige dos projetistas conhecimentos e sensibilidade suficientes para interligar as dimensões humanas com o espaço interior (PANERO, ZELNIK, 1996). Nesse conjunto, a ergonomia se insere como uma disciplina científica relacionada ao entendimento das interações entre os seres humanos e outros elementos ou sistemas, e à aplicação de teorias, princípios, dados e métodos a projetos, a fim de otimizar o bem-estar humano e o desempenho global do sistema, de modo a torná-los compatíveis com as necessidades, habilidades e limitações das pessoas (IEA, 2015). 


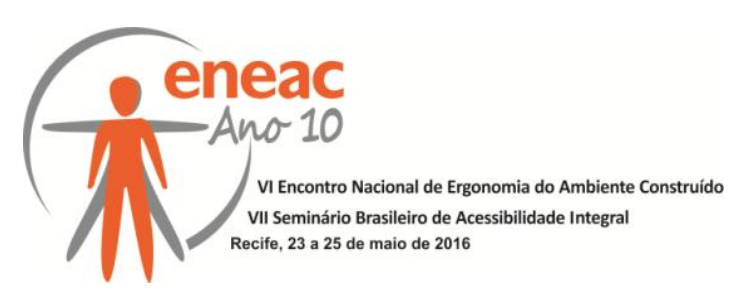

\section{DISCUSSÃO}

A prática da ergonomia se dedica à aplicação de conhecimentos científicos sobre o homem na organização do trabalho, na concepção de ferramentas e na implantação de sistemas de produção (SANTOS, FIALHO, 1997).

O ambiente construído é composto por fatores físicos que determinam as condições ambientais: temperatura, ventilação, iluminação e ruído. Os fatores ambientais influenciam o comportamento humano, pois os estímulos do ambiente físico repercutem sobre a satisfação do indivíduo e no seu desempenho.

O ambiente construído deve apresentar características físicas de caráter prático-utilitário que correspondem aos aspectos mecânicos da função e da atividade desenvolvida no ambiente. Assim, na abordagem ergonômica, ao se centrar nas atividades dos indivíduos, a variabilidade humana passa a ser um parâmetro de projeto em que se consideram as capacidades e limitações variadas dos indivíduos (ATTAIANESE, DUCA, 2012).

No intuito de responder às necessidades do cliente e futuros usuários do edifício, o processo de projetar com ergonomia deve buscar benefícios trazidos pela introdução de princípios e técnicas de ergonomia, desenvolvendo soluções para os problemas do local de trabalho (DUCA, 2014; CAPLANA, 1990). Utilizar uma abordagem ergonômica para focar as interações entre o ambiente e o usuário requer o exame dos efeitos do ambiente sobre a pessoa que o está utilizando, ao se centrar nas atividades dos indivíduos, passando a variabilidade humana a ser um parâmetro de projeto no qual se considera as capacidades e limitações variadas dos indivíduos.

A contribuição ergonômica no projeto pode ser aplicada em projeto do macro espaço, no qual se avalia o espaço global de uma edificação e a organização do trabalho; em projeto do micro espaço, no qual se estuda as unidades produtivas, os postos de trabalho, o trabalhador e seu ambiente imediato; e em projeto detalhado, no qual se observa as características da interface entre o homem, a máquina e o ambiente, chegando a detalhar os instrumentos apropriados à exigência do trabalho. Neste processo, para se desenvolver os projetos, seria necessária a análise da atividade, o arranjo físico do posto de trabalho, o dimensionamento do posto de trabalho, a construção e teste do modelo e ajustes individuais (IIDA, 2005).

Em sistemas centrados no ser humano, a abordagem ergonômica ao projeto de edificação permite antecipar os efeitos do ambiente sobre as pessoas, superando o uso de referências estereotipadas que não refletem a realidade, baseados em suposições sobre as expectativas dos usuários e necessidades, não incluindo no processo os requisitos dos utilizadores. Busca-se, dessa forma, uma interseção entre a análise ergonômica e análise do ambiente, aumentando o programa de necessidades de um projeto de ambiente construído para proporcionar um local para abrigar as necessidades detectadas, bem como para os anseios, saindo das percepções pessoais para caracterizá-los em um quadro teórico, realizando-se estudos de caso em ambientes com características semelhantes as do assunto a ser projetado, estimulando uma investigação nas atividades previstas no programa e nas condições onde ocorrem. A ênfase passaria a ser concentrada na verificação das condições de habitabilidade do ambiente arquitetônico, com foco na relação humana e ambiente, proporcionando a construção crítica do programa arquitetônico, se tornando referência para a elaboração da composição formal.

O ponto de partida para todo o projeto seria, então, uma compreensão das funções do espaço e dos indivíduos específicos que irão ocupar o espaço, exigindo uma tomada de consciência dos comportamentos dos usuários e respostas para as condições físicas dos ambientes. Recomendações com base nos resultados dessas pesquisas ajudariam os projetistas a criar espaços que permitam ocupá-los com conforto. 


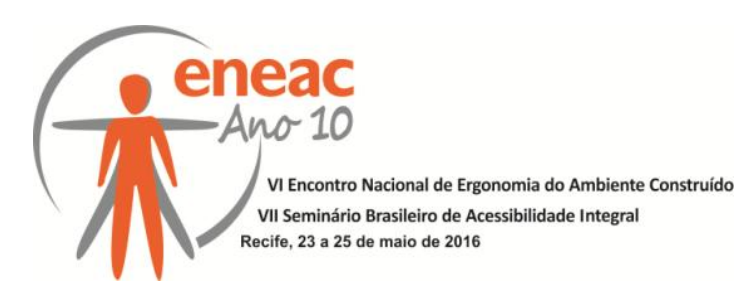

\section{CONSIDERAÇÕES FINAIS}

A racionalidade analítica das técnicas de projeto não pode ser dispensada, mas deve-se atentar que há variáveis humanas que influem no processo de concepção de ambientes. Partindo disso, deve-se propor um processo de projeto alicerçado no sistema humano, no sistema ambiental e no sistema do edifício, que apontam que demandas, necessidades e requerimentos devem ser considerados na hora de projetar o edifício. No sistema humano, os requerimentos do usuário dão origem ao programa de atividades com as respectivas necessidades físicas, ambientais e sociais; o sistema ambiental abrange as características exteriores e o sistema do edifício faz uso dos resultados de necessidades ambientais de cada atividade e do seu cruzamento com as determinações do entorno. Esse processo interativo de aproximar as soluções formais dos fatores humanos contribui para a estruturação ergonômica da configuração do espaço construído.

\section{REFERÊNCIAS}

ATTAIANESE, Erminia; DUCA, Gabriella. Human factors and ergonomic principles in building design for life and work activities: an applied methodology. Theoretical Issues in Ergonomics Science, Vol. 13 Issue 2, p187-202. 2012

CAPLANA, Stanley. Using focus group methodology for ergonomic design. Ergonomics. Volume 33, Issue 5, - pages 527-533. 1990

DUCA, Gabriela. From energy-efficient buildings to energy-efficient users and back: ergonomic issues in intelligent buildings design. Intelligent Buildings International. Pages 215-223. Volume 6, Issue 4, 2014

GRAEFF, Edgar Albuquerque. Edifício. Cadernos Brasileiros de Arquitetura, Volume 7. Projeto Editores Associados Ltda. São Paulo.1986

IAB- Instituto de Arquitetos do Brasil. Anotações sobre o PROJETO em Arquitetura. Contribuição para a sua regulação profissional. Rio de Janeiro. 2013

IEA. The International Ergonomics Association. Disponível em: http://www.iea.cc/ whats/index.html. Acessado em 13/10/2015

IIDA, Itiro. Ergonomia: projeto e produção. 2ª edição - São Paulo: Blucher, 2005

NIEMI, Jessica; LINDHOLM, Anna-Liisa. Methods for evaluating office occupiers' needs and Preferences. Journal of Corporate Real Estate, Vol. 12 Iss: 1 pp. 33 - 46. 2010

PANERO, Juluis; ZELNIK, Martin. Dimensionamento humano para espaços interiores. $1^{\text {a }}$ Edição, 4ํㅡㄹ impressão. Editorial Gustavo Gili, SL, Barcelona. 2008.

SANTOS, N. dos; FIALHO, Francisco. Manual de Análise Ergonômica do Trabalho. 2. ed. Curitiba, Gênesis Editora, 1997. 